\title{
Cobalt Complexes of Polypyridyl Ligands for the Photocatalytic Hydrogen Evolution Reaction
}

\author{
Evelyne Joliat-Wick, Mathias Mosberger, Nicola Weder, Bernhard Spingler, Benjamin Probst, and \\ Roger Alberto*
}

\begin{abstract}
The reductive part of artificial photosynthesis, the reduction of protons into $\mathrm{H}_{2}$, is a two electron two proton process. It corresponds basically to the reactions occurring in natural photosystem I. We show in this review a selection of involved processes and components which are mandatory for making this light-driven reaction possible at all. The design and the performances of the water reduction catalysts is a main focus together with the question about electron relays or sacrificial electron donors. It is shown how an original catalyst is developed into better ones and what it needs to move from purely academic homogeneous processes to heterogeneous systems. The importance of detailed mechanistic knowledge obtained from kinetic data is emphasized.
\end{abstract}

Keywords: Electron relays · Hydrogen · Macrocycles · Photocatalysis · Polypyridyl complexes

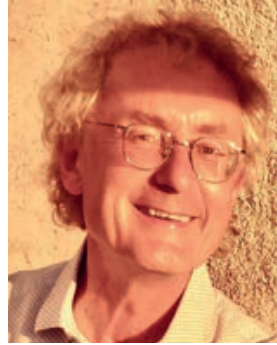

Roger Alberto got his PhD in Chemistry at ETHZ. After postdocs at the TU Munich (W.A. Herrmann) and Los Alamos National Laboratory (A. Sattelberger) on organometallic technetium complexes, he joined PSI (A. Schubiger) for radiopharmaceutical studies with Tc-99(m) and other radionuclides. Appointed associate professor at the University of Zurich in 2000 and full professor in 2006, fundamental chemistry of radioelements and applications in imaging is a focus for which he was awarded with an Alexander von Humboldt prize in 2017. Artificial photosynthesis is a further research focus. Alberto headed the Department of Chemistry 2013-2016 and the University Research Priority Project 'Light to Chemical Energy Conversion' since 2012.

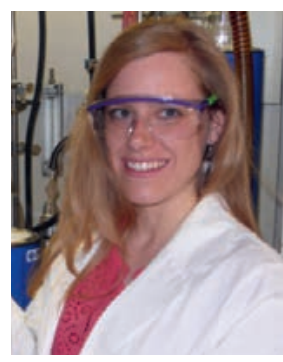

Evelyne Joliat-Wick got her Master of Science in Chemistry as well as the Lehrdiplom für Maturitätsschulen in Chemie at ETH Zurich. After a threemonth research stay in Argentina she joined Roger Alberto's group at the University of Zurich for her PhD studies. There she investigated pyrphyrins and pyrphyrin complexes for light-driven hydrogen evolution. Her main focus was the synthesis of novel pyrphyrins and respective catalysts. She graduated in 2019 and is now teaching chemistry at the Kantonsschule MNG Rämibühl in Zurich.

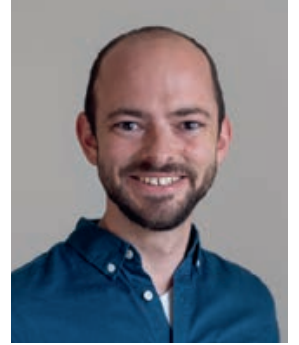

Mathias Mosberger studied Chemistry at the University of Zurich (UZH), where he further pursued his doctoral studies in the group of Prof. Roger Alberto and obtained his $\mathrm{PhD}$ degree in 2020. His undergraduate work focused on tuning the absorption behaviour of a tricarbonyl rhenium(I) photosensitizer-model while maintaining crucial excited state properties. During his graduate studies, he investigated quinonebased redox-pairs as reversible electron shuttle as well as heterogenized molecular systems by derivatizing molecular water reduction catalysts and photosensitizers with suitable anchoring groups in the ligand structure to adsorb and co-adsorb the molecular species on metal oxide nanoparticles.

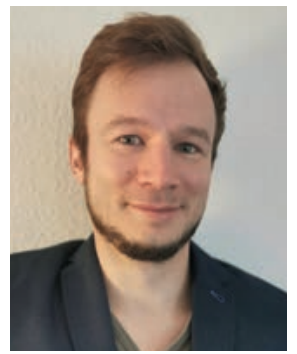

Nicola Weder received his BSc in Chemistry from the University of Applied Sciences (ZHAW) in 2012 and MSc from the University of Zurich (UZH) in 2015. After a short excursus to an industrial lab, he joined the group of Roger Alberto at the University of Zurich for his $\mathrm{PhD}$ with the focus on the immobilization of molecular water reduction catalyst on semiconductor electrodes, which he successfully defended in 2020. Currently, he is working as a Post Doc in the group of David Tilley at the UZH on electro-organic synthesis.

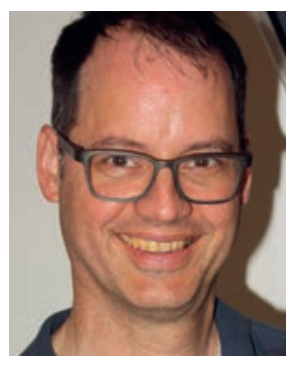

Bernhard Spingler studied Chemistry at the University of Basel. From the same institution he obtained his $\mathrm{PhD}$ degree on the topic of nitrogen-stabilized carbanions (1995-1998). He did a two-year Postdoc with Prof. Stephen J. Lippard at MIT, before starting his career at the University of Zurich (2009: Privatdozent, 2016 Titularprofessor). His current research interests are two-fold: photodynamic therapy and crystallography. 


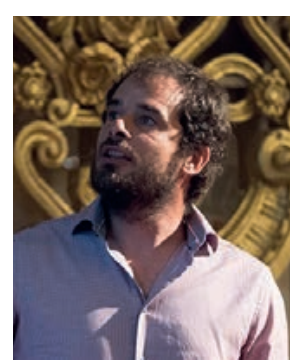

Benjamin Probst is Senior Research Associate in the group of Roger Alberto, University of Zurich. His research interests center on the topic of artificial photosynthesis and solar fuels. He supervises the synthesis of novel, first row transition metal-based water reduction catalysts and photosensitizers. He is closely involved in mechanistic investigations including electrochemical and (time resolved-) spectroscopic methods. Dr. Probst obtained his PhD degree in 2010 from the University of Zurich, with a thesis entitled 'Photocatalytic Hydrogen Production'. He then moved to Andreas Borgschulte at EMPA in Dübendorf for a postdoctoral stay to work on the Sabatier reaction. In 2013 he joined the URPP LightChEC at the University of Zurich as a Research Associate.

\section{Introduction}

In view of the many current societal challenges, the storage of solar light energy in chemical bonds is probably one of the most urgent. ${ }^{[1]}$ Due to the foreseeable energy shortages and the climate change, sustainable energy resources are the only way of ensuring and improving life quality and progress in any sense for the long-reaching future. ${ }^{[2]}$ Availability of solar fuels connects obviously to environmental challenges such as the imminent climate change by providing an unlimited and carbon-free access to energy in gaseous or liquid forms. ${ }^{[3]} \mathrm{New}$ sources for oil and gas are continuously explored. Their discoveries make the consumption of fossil fuels look endless but it is clear for prescient people that one day, closer or farther away, it will for sure become exhausted or unaffordable for simple mobility or heating purposes. ${ }^{[4]}$ The unavoidable consequence is to find timely alternative energy sources. It is obvious that these must ultimately come, directly or indirectly, from the sun. ${ }^{[5]}$ The conversion of indirect solar energy sources such as wind, water or tides into electricity and in fuels is technically well developed (albeit sometimes not very efficient). ${ }^{6]}$ Electricity can be used to electrolyze water, which has been developed in processes with high efficiencies. ${ }^{[7]}$ Liquefaction of the resulting hydrogen $\mathrm{H}_{2}$ to fuel, ideally together with $\mathrm{CO}_{2}$ harvested from the atmosphere via the Fischer-Tropsch process, has been long established. ${ }^{[8]}$ Another but less considered option is the use of the so-produced $\mathrm{H}_{2}$ for conversion of $\mathrm{N}_{2}$ into $\mathrm{NH}_{3}$, one of the processes consuming huge amounts of $\mathrm{H}_{2}$ produced nowadays essentially from coal and gas. Photovoltaic cells (PV cells) can contribute to the job equally well but energy densities from direct light are generally lower than the ones from wind or water. A recent method of using solar light directly is thermochemical water splitting, combined with $\mathrm{CO}_{2}$ reduction on $\mathrm{CeO}_{2}$. Focusing sunlight on $\mathrm{CeO}_{2}$ expels some $\mathrm{O}_{2}$, i.e. reduces the cerium. Passing water or $\mathrm{CO}_{2}$ over this reduced catalyst produces $\mathrm{H}_{2}$ or alternatively $\mathrm{CO}$. The two reactions can be done stepwise, one after the other, and the products subjected to Sabatier or Fischer Tropsch processes to produce $\mathrm{CH}_{4}$ or liquid fuels. ${ }^{[9]}$ Following nature's model, a direct storage of solar energy without wires is an attractive option. This field is referred to as 'artificial photosynthesis' (AP). [10] Bypassing electricity, the direct conversion of solar light into $\mathrm{H}_{2}$ by an unbiased system requires many components and reaction steps interplaying with each other in a concerted way. A synoptical representation of AP is given in Scheme 1. It comprises charge separation by light excitation, called the reaction center in natural photosynthesis, charge and hole transports to the respective catalysts and formation of $\mathrm{H}_{2}$ and $\mathrm{O}_{2}$ respectively. ${ }^{[11]}$ Mimicking this system can be done in multiple arrangements with molecular catalysts or materials, charge carriers and dyes playing an essential role. A few working systems have been reported but they all suffer from rapid decomposition or very low efficiencies. ${ }^{[10,12]}$ Some aspects of designing and developing molecular components for AP, water reduction catalysts (WRC) in particular, are described in this review article, including some unpublished results for showing the challenges to be overcome when aiming at producing a full, light-driven water splitting system.

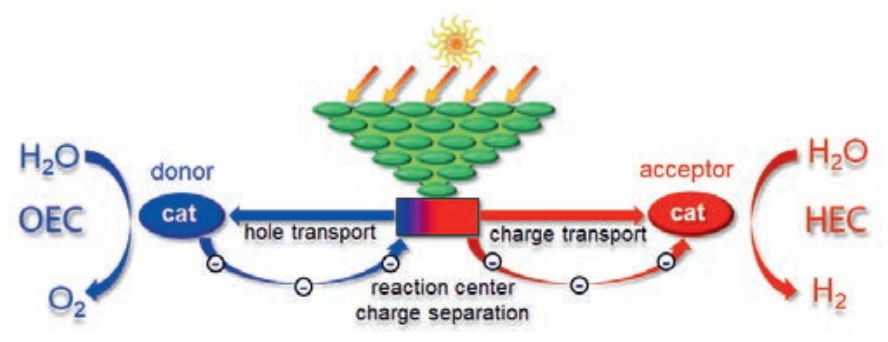

Scheme 1. Steps in artificial photosynthesis; excitation and charge separation upon light irradiation, electron transport to hydrogen evolving catalyst (HEC) and hole transport to oxygen evolving catalyst (OEC). Either component can be molecular.

\subsection{Mechanistic Concepts in Artificial Photosynthesis}

A complete photocatalytic water-splitting architecture consists of a water oxidation site, where the so-called oxygen evolution reaction (OER) takes place with a respective catalyst (OEC). At the opposite site, water reduction to hydrogen $\mathrm{H}_{2}$ is catalyzed in the hydrogen evolution reaction (HER) with a corresponding catalyst (HEC). The two sites are spatially separated from each other and are generally investigated in separate studies. ${ }^{[10,13]}$ Eventually, they may be combined into a single functional device. If the processes are separately investigated, the OER requires sacrificial electron acceptors (SEA, oxidants), mimicking the reductive branch in natural photosynthesis, i.e. photosystem I. On the other hand, HER requires a sacrificial electron donor (SED). The best way to couple the two catalytic systems, biased or unbiased, in an applicable device is controversially discussed. ${ }^{[14]}$ It is, however, clear that the two reactions will not be combined in a fully homogeneous setup, spatially separated or not, since too many shortcuts between the different compounds of opposite nature will prevent the reaction from working. Realistically, a full system will be built up from molecules or materials or both, and is separated into a photocathode compartment for HER, and in a photoanode compartment for OER, and a linkage to allow proton and electron transfer (Scheme 2). The actual water-splitting reactions may then run with molecular catalysts grafted to the surface of the semiconducting light absorbers or with the materials by themselves as for instance with $\mathrm{MoS}_{2}{ }^{[15]}$ The question "molecules or materials" is regularly discussed in the community and there are pros and cons for both. ${ }^{[10,11]}$ There is of course the option for combining both, molecules and materials, meaning that catalytically active molecules are grafted onto a photochemically active support in which the charge separation takes place. ${ }^{[16]}$ Such an architecture refers to photoelectrochemical cells or systems (Scheme 2).

Our group focuses on molecular catalysts with the distinct intention of later adsorption on materials. Methodologically, molecular catalysts have the advantage that they can be investigated in homogeneous solution. This allows for the determination of physico-chemical characteristics such as electrochemical data, rate constants of individual elementary reaction steps or turnover frequencies (TOFs) for the entire system, as well as performances with respect to catalyst stabilities (turnover numbers TONs). Detailed mechanistic information with ultra-fast spectroscopic methods can be gained about rate-limiting steps or the nature of intermediates. Once such features are known, one can proceed to study the molecular catalysts adsorbed on suitable materials, the process is carried from purely homogeneous to heterogeneous catalysis. It is obvious that mechanisms are not necessarily the 


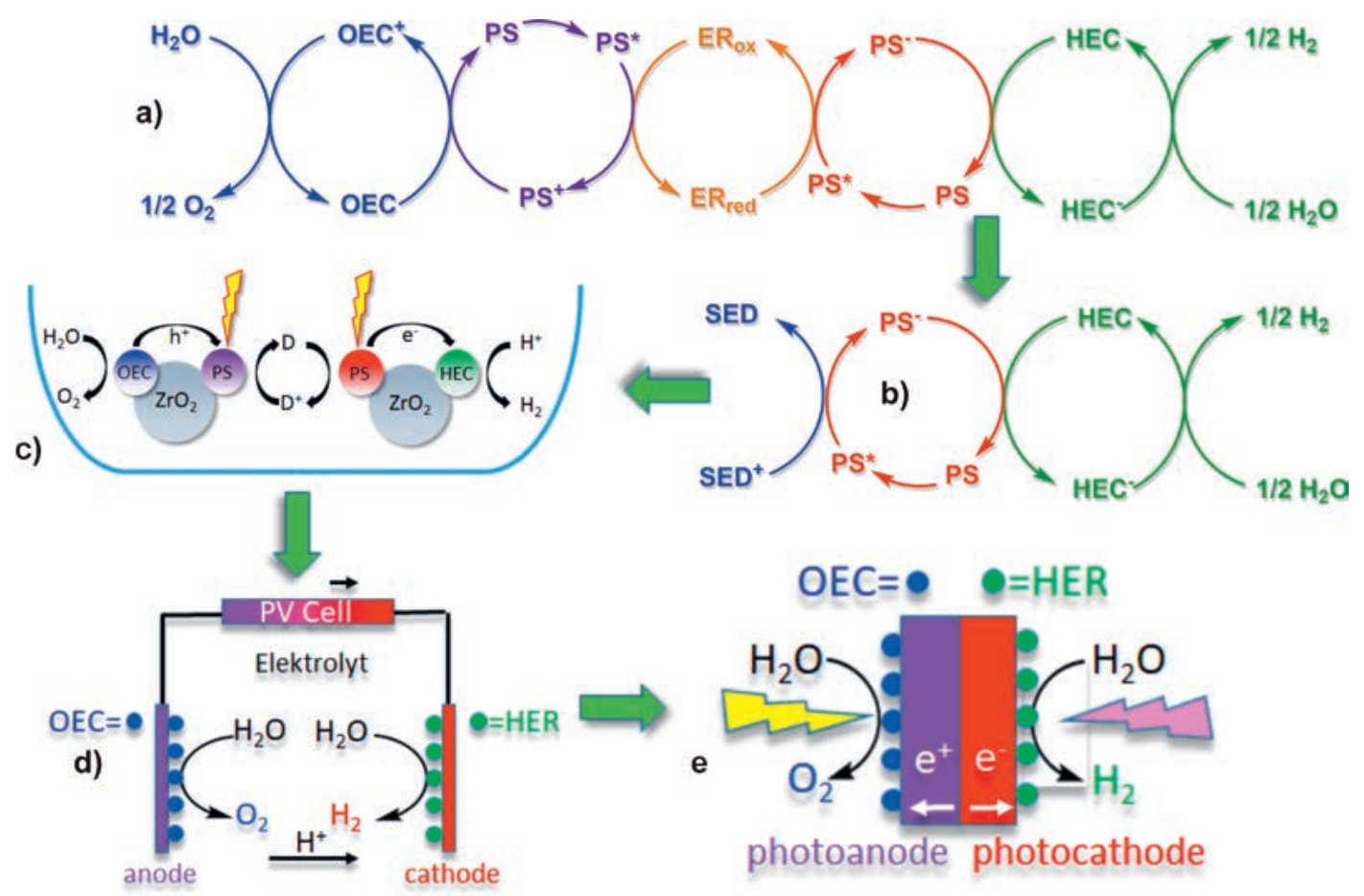

Scheme 2. Elementary steps in a full water splitting system (a), the blue part corresponds to PSII and the green part to PSI in the natural photosystem. For studying the HER, the water oxidation part is replaced by an sacrificial electron donor (b). Grafting the two components on particles as a first step towards heterogenization (c) ${ }^{[19]}$ or grafting the HER and OER on electrodes for electrochemical water splitting driven be e.g. a PV cell (d). ${ }^{[12 e]}$ The famous artificial leaf using a tandem cell for photoelectrochemical water splitting (e). ${ }^{[12 b]}$

same in homo- or heterogeneous architectures, but analyses in solution may indicate intermediates or rate-determining steps for both systems. Furthermore, more efficient catalysts can only be designed rationally if such thermodynamic and kinetic information is available. Our research over the past years focused on HER and we went through these steps, thorough iterative investigations of photocatalytic reactions in solution and proceeding to heterogeneous systems with our best catalysts. A focus was put on cobalt catalysts since a wide range of information was already available and cobalt proves to be an excellent metal center for HER. ${ }^{[17]}$ Starting from the dimethylglyoximate $\left(\mathrm{dmgH}_{2}\right)$ complexes of $\mathrm{Co}^{\mathrm{III}},\left[\mathrm{Co}(\mathrm{dmgH})_{2} \mathrm{X}_{2}\right],{ }^{[18]}$ we proceeded to acyclic and cyclic poylpyridyl ligands and cobalt complexes, respectively. To exemplify the advancement in catalyst development made over the past years, a few examples are reported in this article that should demonstrate the progress based on the methodology described before. A selection of catalytic sequences is given in Scheme 2, showing some of the elementary steps of the full system (a) and truncated by the OER (b). Both HER and OER may be grafted on particles in a first step towards heterogenization (c). ${ }^{[10,19]}$ Binding the OER and HER on electrodes gives a system which may be driven electrochemically by PV (d) ${ }^{[12 \mathrm{e}]}$ cells or coupled together in a tandem cell (e). ${ }^{[12 b]}$ Catalysts for all schemes may be molecular or materials. In this article, a main focus will be put on a) and b) with cyclic and acyclic polypyridyl-based, molecular catalysts.

\section{Acyclic and Cyclic Polypyridyl Ligands and their Cobalt Complexes for HER}

To perform HER, the metal center should accommodate at least three oxidation states, one of which being the resting state. Furthermore, it should have one position available at which the $\mathrm{H}_{2}$ formation can take place. The first step in HER is typically the protonation of an electron-rich, eventually pre-reduced metal centre. Subsequent steps include the protonation of the formed hydride to finally generate and liberate $\mathrm{H}_{2}$. There are many scenarios which combine some of these steps such as proton-coupled electron reductions. Elementary steps may be altered in their sequences, yielding principally the same product. Sequences may depend on the particular conditions, the catalysts and the other components. Each system, which has been changed to a certain extent should be re-investigated since mechanisms may change and occur sometimes even in parallel.[20] Based on these considerations, many groups with research in the HER focus on cobalt, iron or nickel, if staying in the first transition metal series. Since pyridines generally form stable complexes with these elements, respective ligands and catalysts were in the focus with a basketlike pentapyridyl ligand or with amino-polypyridyl complexes and others. ${ }^{[21]}$ Complexes being structurally more distorted from an ideal coordination geometry are typically more reactive according to the entatic-state principle.[22] We therefore focused initially on pentapyridyl ligands, which would not offer an ideal coordination geometry.

\subsection{HER with Acyclic Pentapyridyl Ligands and Cobalt Complexes}

The pentapyridyl ligand di([2,2'-bipyridin]-6-yl)(pyridin2-yl)methanol was synthesized as shown in Scheme 3. As a ligand also with a denticity of five but with lowered symmetry than the basket-like pentapyridyl ligands, this ligand consists of two 2,2'-bipyridine units and a single pyridyl donor, preorganized in an arrangement that is not ideal for pentadentate coordination. Indeed, when analyzing the strongly distorted octahedral geometry, one could also describe it as a distorted trigonal prismatic geometry. The X-ray structure analyses of the symmetric complex $\left[\mathrm{Co}^{\mathrm{II}}(\mathrm{ppy}) \mathrm{Br}\right]^{+}$and the distorted complex $\left[\mathrm{Co}^{\mathrm{II}}(\mathrm{appy}) \mathrm{Br}\right]^{+}(\mathbf{1})$ are shown in Fig. 1.[23]

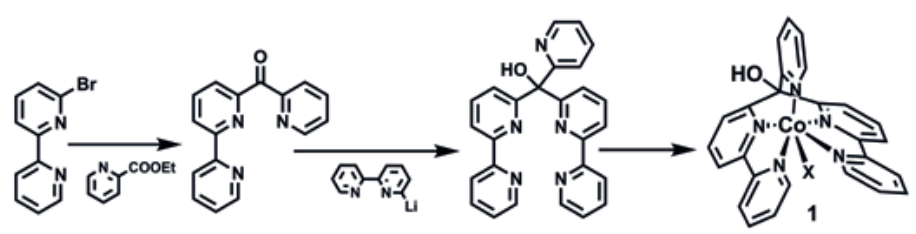

Scheme 3. Preparation of complex 1 comprising a distorted pentapyridyl ligand. ${ }^{[23]}$

HER catalysis was performed with the two complexes to evaluate the structural/geometrical influence of a ligand with the same donors and the same denticities. Interestingly, the TONs were for both catalysts about the same, albeit after very different times. 

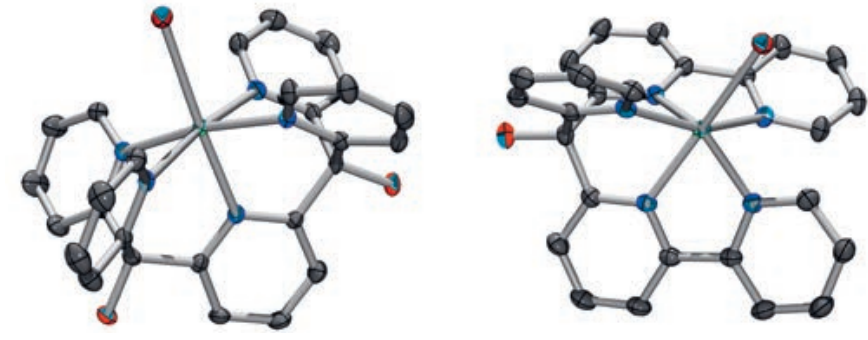

Fig. 1. X-ray structure analyses of a symmetric and an asymmetric HER with pentapyridyl ligands. ${ }^{23]}$

The distorted complex was 8-10 times faster in the concentration range $<5 \mu \mathrm{M}$, but catalysis stopped after a comparably short time. Above $5 \mu \mathrm{M}$, TOFs and TONs were comparable, clearly indicating that a process different from the catalytic turnover at cobalt was rate limiting. In the presence of a comparably large concentration in catalyst, the photocycle becomes rate limiting, i.e. the catalysts do not run at full speed. Below $5 \mu \mathrm{M}$, it is remarkable that the two catalysts show a kind of opposite behavior; the distorted catalyst becomes faster and the turnover numbers increased, whereas the symmetric catalyst became slower and TONs decreased (Fig. 2). The comparison between the two catalysts corroborates the entatic-state principle that should be considered when designing new ligands and the respective HER catalysts. It also indicates that the mechanisms or sequences of reaction steps may be different for the two apparently similar catalysts. ${ }^{[24]}$

The HER catalyst 1 achieved about 33 kTONs under optimized conditions. Analysis of performance limiting factors showed that the photosensitizer (PS), in most cases the classical complex $\left[\mathrm{Ru}(\mathrm{bpy})_{3}\right]^{2+}$ (bpy $=2,2^{\prime}$-bipyridine), was decomposed when $\mathrm{H}_{2}$ formation ceased. Furthermore, the oxidation product of the sacrificial electron donor ascorbic acid (HAsc), dehydroascorbic acid (DHA), caused shortcuts in the cycle by reoxidizing the once quenched photosensitizer. This undesired side reaction was suppressed by adding the reducing agent tris(2-carboxyethyl) phosphine (TCEP) to the catalytic solution. ${ }^{[25]}$ TCEP reduces once formed DHA at high rates. The oxidation of TCEP is irreversible and it therefore acts as a true SED. In this system, HAsc has now turned into an electron relay rather than an SED. The addition of TCEP enhances the achievable TONs substantially, mostly by a factor of three or higher. The progress can be monitored by NMR and at HER catalyst concentrations $>20 \mu \mathrm{M}$ TCEP is used up quantitatively. HER ceases after TCEP is fully converted into its oxide (see also section 2.3). To assess if the HEC is still intact at this time point is difficult, since its concentrations are typically very low and range from $100 \mathrm{nM}$ to $5 \mu \mathrm{M}$. Spectroscopic methods are not helpful due to the presence of high concentrations of other components, which hide eventual characteristic absorption bands. One possibility to evaluate the stabilities of HECs is to adsorb them on particles, separate the used-up catalytic solutions containing all other components and add fresh media. If catalysis resumes, one can indirectly assume that the HEC is still intact. Surface sensitive methods such as XPS may even directly support the intact nature of the catalysts or other components (vide infra).

As a step towards heterogeneous catalysis, non-covalent grafting of the HECs and PSs, derivatized with long alkyl chains on e.g. hydrophobic, reversed-phase particles, is a convenient option. Silica nanoparticles can be decorated with alkyl-chains by reaction with e.g. trialkyl-silylchlorides. Correspondingly alkylated catalysts will then strongly bind to these carriers by hydrophobic interactions. The acyclic pentadentate ligands and their complexes were heterogenized along this way subjected to photocatalysis. ${ }^{[23 a, 26]}$ There are different compositions for assessing the different elementary steps in such setups. The HER catalyst can be bound to the particles and the other components are in solution. A more attractive alternative is to have both bound to the surface. Using the hydrophobic interactions between $\mathrm{C}_{18}$ modified particles and catalysts, the high mobility of HER and PS in the $\mathrm{C}_{18}$ layer on the particles will allow electron transfer from the reductively quenched PS to the HER catalyst. Once the HER ceases, the medium can be replaced by a fresh one. If catalysis resumes, the HER catalyst is still intact. Such a study was done with the pentapyridyl catalyst $\mathbf{1}$, derivatized with $\mathrm{C}_{18}$ chains $\left(\mathbf{1}-\mathbf{C}_{\mathbf{1 8}}\right)$. The standard $\left[\mathrm{Ru}(\mathrm{bpy})_{3}\right]^{2+}$ was mono-functionalized with a $\mathrm{C}_{19}$ alkyl-chain $\left(\mathbf{R u}-\mathbf{C}_{19}\right)$ and co-grafted to the reverse-phase particles. Immersing the particles in an aqueous solution comprising a buffer and the SED, catalysis resembles the one shown in Scheme 1c with the OER replaced by the SED (Scheme 4). ${ }^{[26]}$

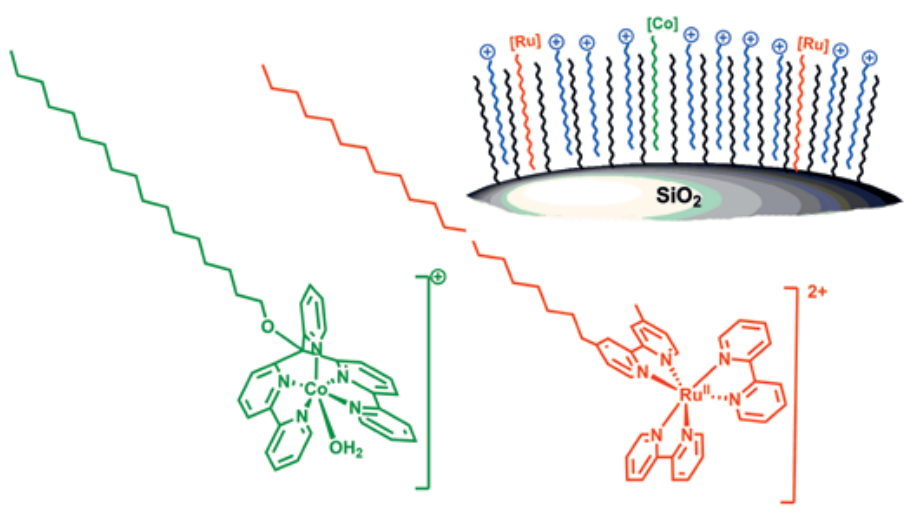

Scheme 4. Non-covalent grafting of HEC and PS on silica particles; photosensitizer (red), HER based on 1 (green) and surfactants (blue). ${ }^{[26]}$

This comparably simple system showed two fundamental results. At low concentrations in HEC and PS, the $\mathrm{H}_{2}$ production exceeded the one of a homogeneous system by far (Fig. 3, left). While rates become diffusion limited in solution, the local concentrations of PS and HEC on the surface of the silica particles are still high and the reaction persists. Furthermore, exchanging the
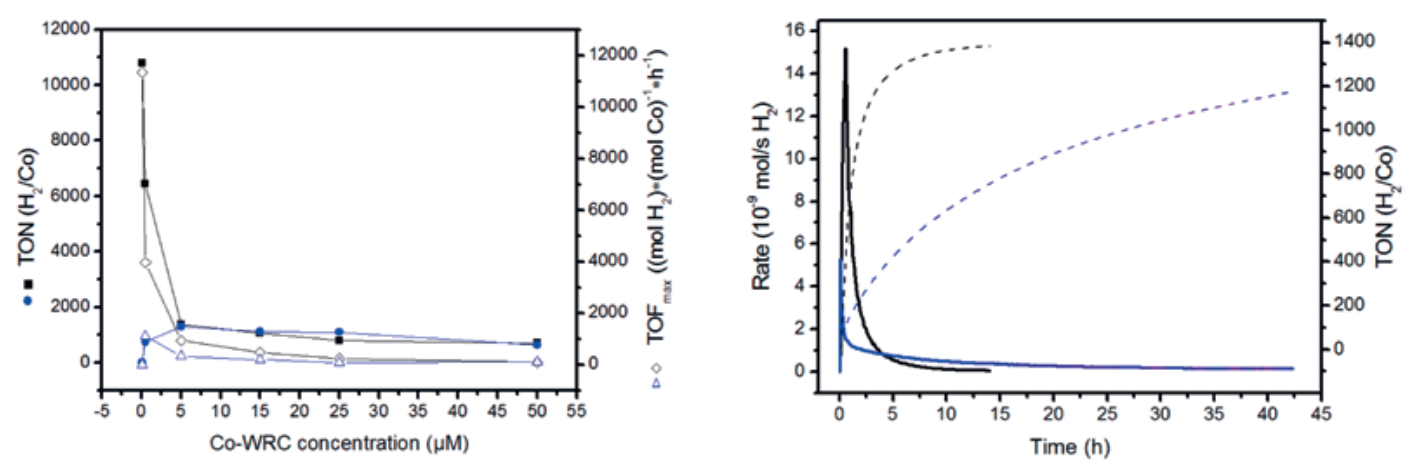

Fig. 2. Left: Cobalt concentration dependency with HEC 1 (black) and its symmetric counterpart (blue). Right: Rate profiles (bold) and $\mathrm{TON}_{\mathrm{Co}}$ (dashed) for the two HECs at $5 \mu \mathrm{M}$ concentration. (500 $\mu \mathrm{M}[\operatorname{Re}(p y)(C O))_{3}$ bipy](OTfls), $1 \mathrm{M}$ ascorbic acid, $\mathrm{pH} 4.1,10 \mathrm{ml}$ $\left.\mathrm{H}_{2} \mathrm{O}\right)$. [24b] 
Fig. 3. Left: comparison of rates (solid lines) and amounts of $\mathrm{H}_{2}$ (dashed lines) for homo- and heterogeneous photocatalytic reactions; $20 \mu \mathrm{M}$ Ru- $\mathbf{C}_{19}$ and $1 \mu \mathrm{M}$ 1-C $\mathbf{C}_{18}$ immobilized on alkylated silica (black, heterogeneous), $20 \mu \mathrm{M}$ PS and $1 \mu \mathrm{M} 1$ (red, homogeneous), $10 \mu \mathrm{M} \mathbf{R u}-\mathbf{C}_{19}$ and

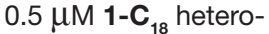

geneous (grey) and $10 \mu \mathrm{M}$ PS and $0.5 \mu \mathrm{M} 1$ homogeneous (magenta). Right: Repetition of catalysis after replacing media after each cycle. ${ }^{[23 a, 26]}$
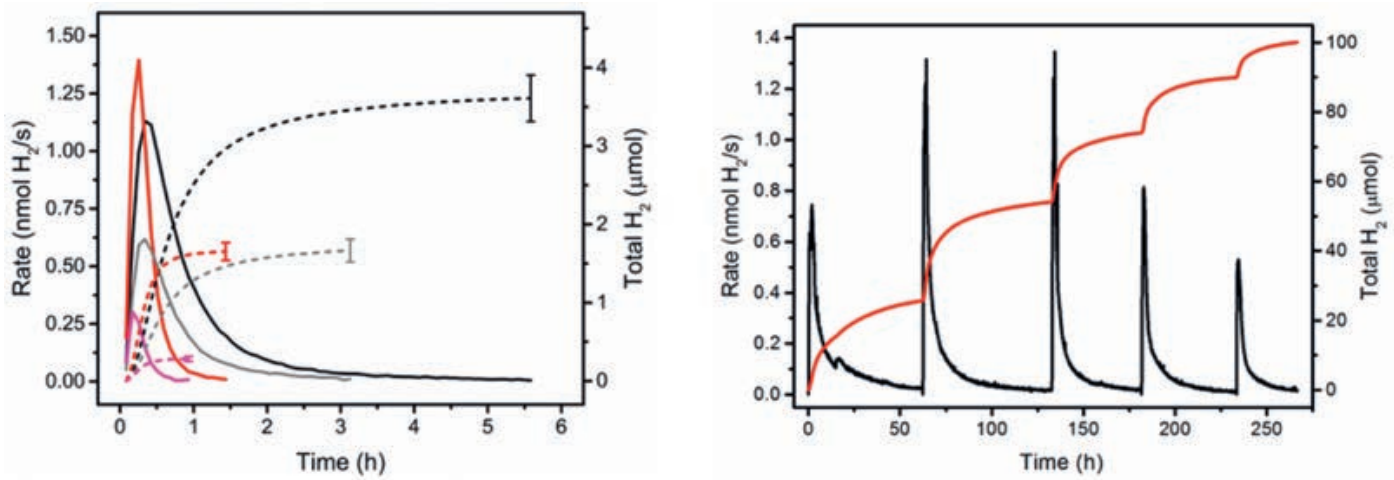

media in such a heterogeneous catalysis assesses the intactness of the catalyst, if $\mathrm{H}_{2}$ formation re-establishes. This was the case and the catalysis resumed for at least six cycles (Fig. 3, right). Some loss of reactivity was noted probably because part of the components are lost during the filtration processes (Fig. 3). The reductively quenched PS has a relatively short life-time if the electron is not transferred to an acceptor. At high dilution, this does happen only very slowly and the PS decomposes relatively fast. On the hydrophobic surface, the $\mathrm{PS}^{-}$can transfer its electron comparably rapidly to a WRC and does decompose to a smaller extent than in solution. ${ }^{[26]}$

\subsection{HER with Cyclic Tetrapyridyl Ligands}

For providing higher complex stabilities, macrocyclic ligands are better suited than their acyclic counter-parts. The enhanced stabilities are mainly of kinetic origin since macrocycles are much less flexible than open systems. A better adapted chelate effect, provided that the metal-ion fits in the cavities of the macrocycles, adds to these stabilities. Tetrapyrroles in general and porphyrin complexes in particular are prototypical macrocycles investigated in essentially all fields of science. They were also applied for HER albeit not with much success. ${ }^{[27]}$ More commonly, they have been studied with great success in electrocatalytic $\mathrm{CO}_{2}$ to $\mathrm{CO}$ reduction. ${ }^{[28]}$ Much less common are macrocyclic tetrapyridyl ligands and complexes. One of the first ligands of this kind and corresponding complexes were synthesized by Ogawa and coworkers. ${ }^{[29]}$ The basic ligand scaffold consists of two bipyridyl subunits, which are mutually connected by a carbonitrile bridge (Scheme 5a). This ligand could tautomerize to a fully conjugated system (Scheme 5b). Theoretical calculations indicated
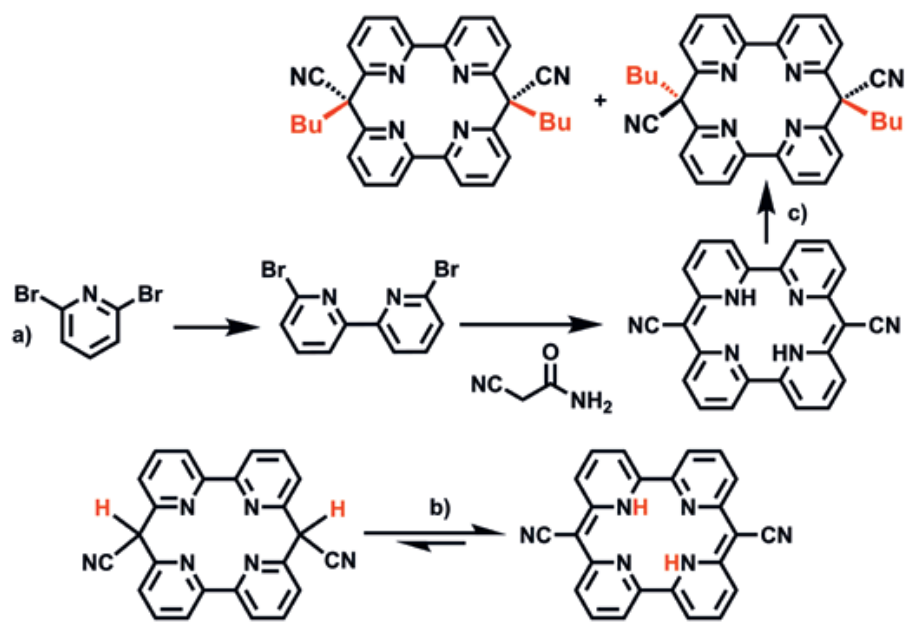

Scheme 5. Synthesis of a carbonitrile bridged macrocyclic tetrapyridyl ligand (dicyano-pyrphyrin) (a), tautomeric forms (b) and alkylation at the bridge-head carbons (c). ${ }^{[30]}$ indeed that the tautomerized form with the protons sitting on two pyridine nitrogen atoms is more stable by about $30 \mathrm{kcal} / \mathrm{mol} .^{[30]}$ Coordination to $\mathrm{Co}^{\mathrm{II}}$ would thus lead to a neutral, porphyrin-like complex. This complex could be prepared but was insoluble in any solvent. The fully planar structure of the complex together with the neutral charge induces probably very strong stacking forces and HER with this catalyst could thus not be investigated. It is, however, a slow, but very stable catalyst when employed in an aqueous suspension. ${ }^{[31]}$

To make the ligand and the complexes based on the pyrphyrin scaffold soluble, derivatizations at the carbonitrile bridges would break the planarity and the di-anionic charge of the parent ligand, thereby providing solubility but at the cost of conjugation (Scheme 5c). Alkylation with iodo-alkanes (butyl and pentyl) lead to mono- and bis-alkylation at this position together with cis- and trans-isomers for the latter ones. The corresponding $\mathrm{Co}^{\text {II }}$ complexes could now be subjected to photocatalysis and showed TONs of up to $22^{\prime} 000$ and TOF ${ }_{\max }$ of about $3000 \mathrm{~h}^{-1}$. $^{[30]}$

For application in heterogeneous catalysis, the complexes with the dicyano-pyrphyrin ligands were derivatized with long alkyl chains, as was done before for the acyclic pentapyridyl ligands. As for the butyl and pentyl derivatized ligands, $\mathrm{C}_{18}$ chains were introduced. For both, a mono-, cis- and trans-isomer formed which were separated from each other. Fig. 4a shows an X-ray structure of trans- $\mathrm{C}_{18}$-pyrphyrin ligand. ${ }^{[31-32]}$

Based on the excellent catalytic and chemical properties of the pyrphyrin system, the question about decyanation of dicyanopyrphyrin arose. The resulting methylene-bridge would offer many options to further derivatize the basic ligand structure. Such a new tetrapyridyl ligand was called pyrphin, in analogy to the porphyrinic 'porphin'. It was mentioned in the original publication ${ }^{[29 a]}$ that the cyano groups could be hydrolyzed in $70 \%$ aqueous sulfuric acid at $120^{\circ} \mathrm{C}$, resulting in a dark red product. This procedure was, however, not reproducible and new conditions towards the pyrphin ligand had to be developed. Basic workup led to polymers and working under ambient conditions gave the mono- and the diketo-pyrphins (vide infra). The methylene bridges are thus extremely reactive, full conjugation through the system probably the driving force behind this. Working in trifluoroacetic acid and precipitating the resulting cation as $\left[\mathrm{PF}_{6}\right]^{-}$salt allowed isolation of the doubly protonated pyrphin ligand. An X-ray structure is shown in Fig. 4b. ${ }^{[32]}$

Stabilization of the pyrphin framework by complexation to metals yielded the zinc complex $\left[\mathrm{Zn}(\mathrm{pyr})\left(\mathrm{SO}_{4}\right)\right]$ with the zinc being located above the pyrphyrin plane (Fig. 4c). The same reaction with nickel instead of zinc gave a very uncommon di-nickel complex in a kind of butterfly structure and in good yields (Fig. $4 d)$. The $\mathrm{C}-\mathrm{C}$ bonds between the two pyrphyrins are essentially perpendicular to the complex planes. The formation of these $\mathrm{C}-\mathrm{C}$ bonds reflects the reactivities of the methylene bridges against oxidation. The reaction of a mononuclear, transiently formed com- 


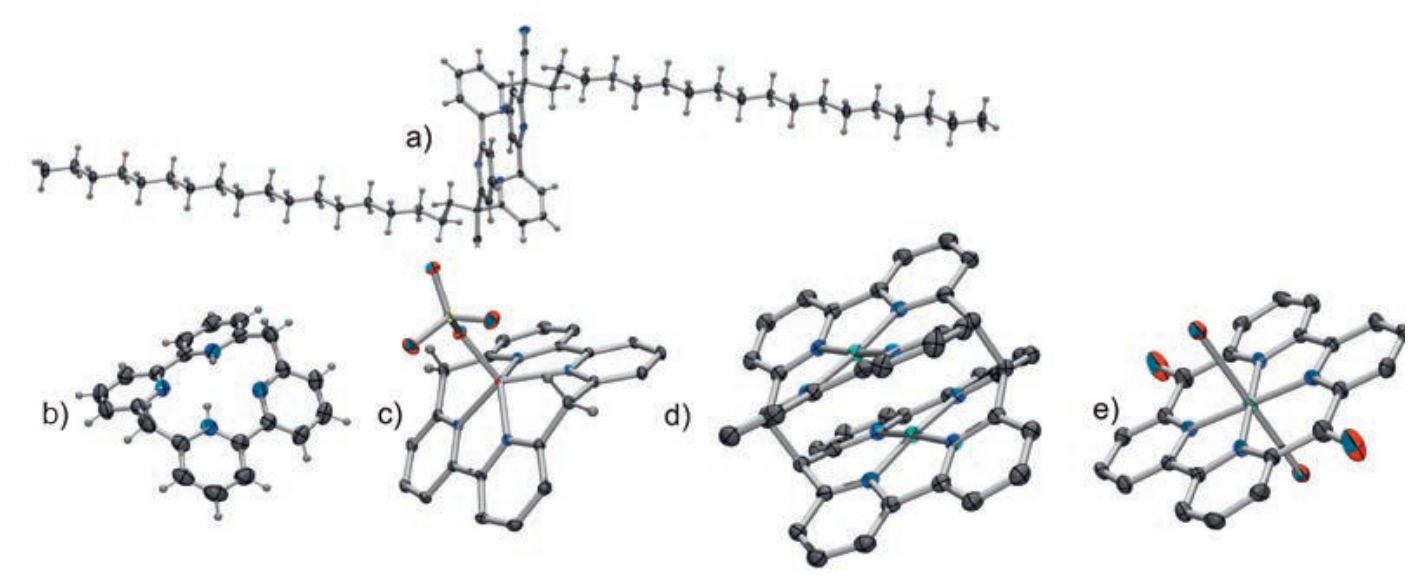

Fig. 4. $\mathrm{A} \mathrm{C}_{18}$-derivatized dicyanopyrphyrin ligand (a), the decyanated pyrphyrin (pyrphin) in its doubly protonated form (two hexafluorophosphate anions omitted for clarity) (b) and the corresponding $\mathrm{Zn}^{2+}$ complex (c). A dimerized nickel complex with the pyrphin ligand (four sulfate, two $\left[\mathrm{Ni}\left(\mathrm{OH}_{2}\right)_{6}\right]^{2+}$ and additional water molecules omitted for clarity) (d, structures a-d from ref. [32]) and the cobalt complex of diketo pyrphin (e). ${ }^{[3]}$

plex $\mathrm{Ni}(\text { pyr })^{2+}$ with $\mathrm{SeO}_{2}$ gave the dinuclear complex in solution in almost quantitative yields. The reaction with cobalt finally gave the diketo-pyrphin complex of $\mathrm{Co}^{\mathrm{II}}$ (Fig. 4e). ${ }^{[33]}$ Since the synthesis via decyanation is tedious and leads to side products, an alternative approach was developed in which the dimethyl-pyrphin ligand was prepared and the two methyl groups oxidized with $\mathrm{CrO}_{3}$ to yield the diketo-pyrphin in very good overall yields. [34] The respective cobalt complex turned out to be an excellent catalyst for the HER reaction and TONs of up to 40'000 could be achieved. After the $\mathrm{H}_{2}$ formation ceased, additional PS and SED was added to the used up solution which re-established photocatalysis to a substantial extent, underlining once more the excellent stabilities of these macrocyclic polypyridyl complexes. [33]

\subsection{Heterogeneous HER with Pyrphyrins}

Moving a step forward towards heterogenizing these macrocyclic ligands, the bridging positions were derivatized with two ethylphosphonates. Phosphonates are often used to bind HECs or OECs to oxidic surfaces such as $\mathrm{TiO}_{2}$ and others. ${ }^{[35]}$ Accordingly, pyrphins derivatized with these groups could serve as HECs on a photocathode or simply as heterogenized nanoparticles in a solution, containing the other components for photocatalysis. Deprotonation of dimethyl-pyrphyrin at the bridgehead carbons and reaction with diethyl-vinylphosphonate esters yielded the respective cis- and trans-forms, which could be separated and transformed into the respective cobalt complexes (Scheme 6). Interestingly, in these complexes, cobalt is preferentially in the +III oxidation state, indicating a low spin state as found in the diketo-pyrphyrin. ${ }^{[33]}$ Photocatalysis was investigated in solution and with the complexes bound to $\mathrm{TiO}_{2}$ particles. A detailed kinetic and mechanistic investigation revealed that there are essentially no differences in the rate constants in solution and on particles. Reduced TONs for the on-particle reaction are explained by the diffusion range of the reduced $\mathrm{PS}^{-}$within its lifetime. Many PS are not in reach of the particle surface and decompose rather rapidly before delivering the electrons to the HER catalyst@ $\mathrm{TiO}_{2}$. Replacing the media by a fresh one resumed catalysis by $60 \%$, indicating the good stability of the bound catalyst. To investigate the long-term stability of the catalyst, it was grafted on an FTO electrode coated with mesoporous $\mathrm{TiO}_{2}$. At a potential of $-0.65 \mathrm{~V}$ vs. SHE, a steady current was measured over $2 \mathrm{~d}$ which coincided with evolved $\mathrm{H}_{2}$ detected in parallel by inline gas chromatography. Over these two days, the catalysts made about 500 kTONs of $\mathrm{H}_{2}$. Furthermore, the indirect proof for an undecomposed HER catalyst was supported by direct XPS measurements. Apart from that, Co $2 \mathrm{p}_{3 / 2}$ and P $2 \mathrm{p}$ levels were analyzed before and after catalysis. Comparison of both spectra confirmed that the catalyst in unchanged configuration was still bound to the surface after catalysis ceased (Fig. 5). The reason for terminated catalysis was rather the decomposition of the FTO electrode than the catalysts themselves. These experiments showed that macrocyclic pyrphins offer an excellent platform for efficient and long-term stable HER catalysts. They also include the option of introducing more functionalities for $e . g$. surface grafting or influencing the electronics of the metal centre to increase the rate of hydrogen formation or decrease the overpotential which is still too high at this point.

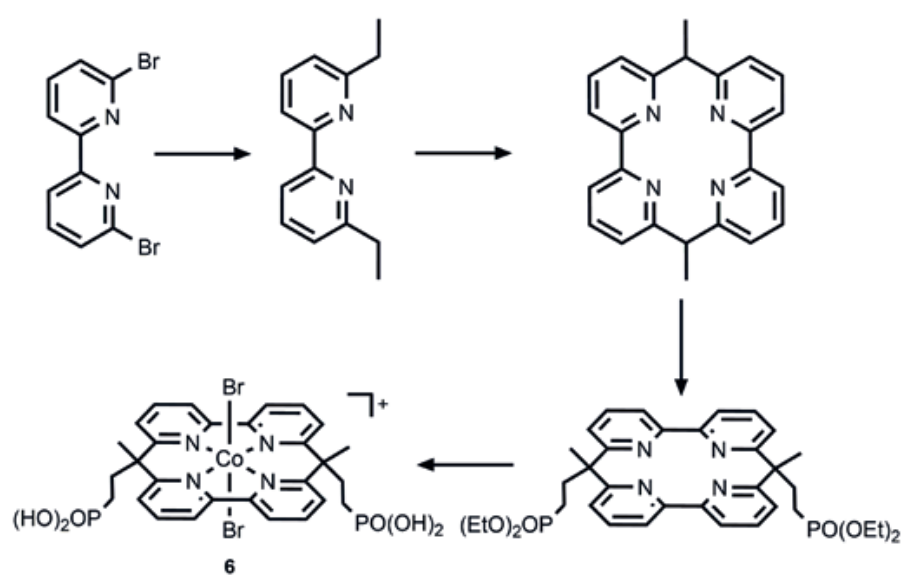

Scheme 6. Synthesis of a di-phosphonated pyrphyrin ligand and its cobalt complex. ${ }^{[36]}$

\subsection{Sacrificial Electron Donors, Electron Relay}

Investigating only one half reaction of the entire artificial photosynthetic system requires a sacrificial electron donor as outlined in the introduction to the concepts. Having the OER and HER catalysts grafted on photoelectrodes needs an electron relay, shuttling holes and electrons in an unbiased architecture. A sacrificial electron donor can be turned into an electron relay, if it is reversibly oxidized and reduced as is the case in $e . g$. the ascorbic acid/DHA pair with the above-mentioned TCEP. Typical SEDs in homogeneous photocatalytic HER are triethylamine and triethanolamine (both irreversible) and ascorbic acid (reversible). There are a few other SED but they are of minor relevance. The natural photosystem uses plastoquinone as a reversible electron shuttle in the thylakoid membrane. Consequently, the question arose if quinones might be suitable electron relays for artificial photosynthesis as well. Quinones have furthermore the advantage over other SEDs that numerous derivatives exist, which influence redox potentials and other physico-chemical properties. Therefore, the use of quinone-based electron relays is quite intuitive. This concept was introduced in the 1980s and quinones and hydroquinones 
Fig. 5. Performance comparison of cobalt HEC with a di-phosphonated pyrphyrin ligand, bound to $\mathrm{TiO}_{2}$ particles (pink, heterogeneous) and in solution (green, orange, homogenous) (left). Core level spectra of Co $2 p_{3 / 2}$ and $P 2 p$ before and after electrocatalysis (right). ${ }^{[36]}$
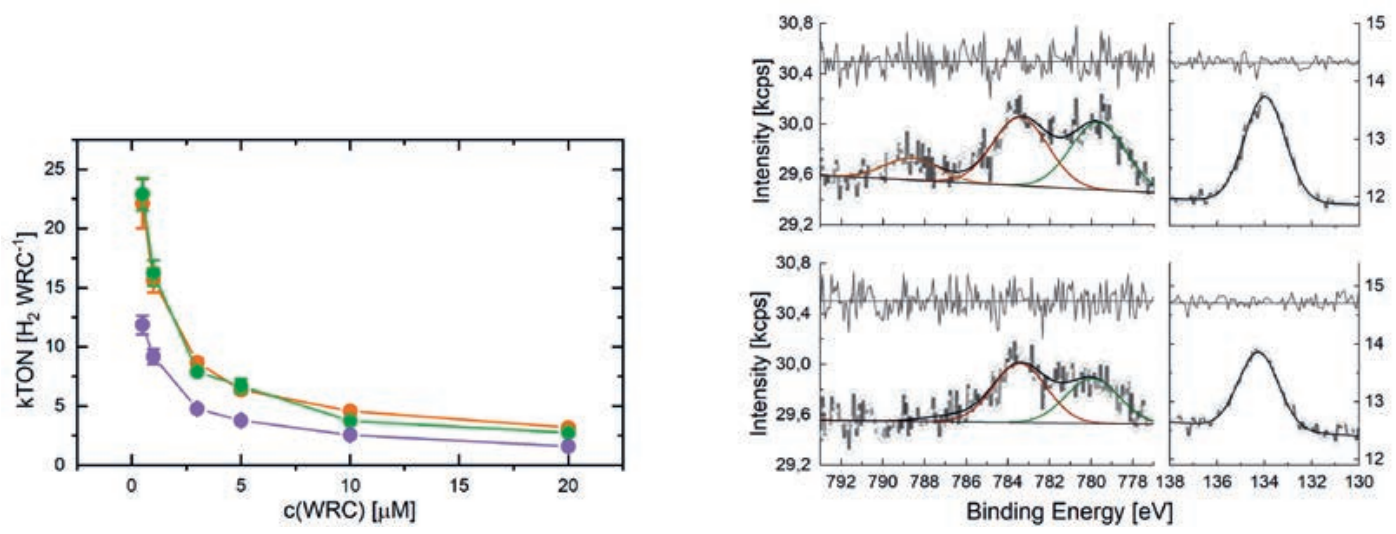
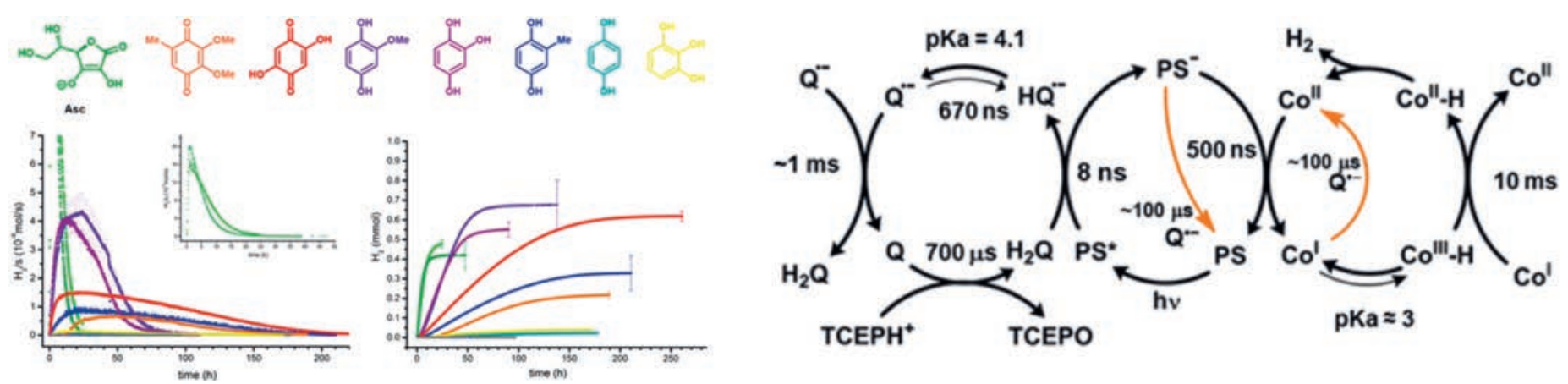

Fig. 6. HER experiments with hydroquinones; $5 \mu \mathrm{M}[\mathrm{CoBr}(\mathrm{aPPy})] \mathrm{Br}(\mathrm{HER}), 0.5 \mathrm{mM}\left[\mathrm{Ru}(\mathrm{bpy})_{3}\right]^{2+}$ (PS), $100 \mathrm{mM}$ relay and $100 \mathrm{mM}$ TCEP in $0.5 \mathrm{M}$ $\mathrm{NaOAc/AcOH}$ buffer at $\mathrm{pH}$ 5. Hydrogen evolution rate vs time (left), ascorbate reference with buffer (dark green) and without buffer (bright green). The total amount of $\mathrm{H}_{2}$ vs time (middle). Overview of identified timescales of the catalytic cycles with fast ET to Co' and slow $\mathrm{H}_{2}$ evolution (10ms), slow regeneration of the oxidized relay and fast recombination of the reduced $\mathrm{Re}$ and Co species with the oxidized relay. ${ }^{[39,40]}$

$\left(\mathrm{H}_{2} \mathrm{Q}\right)$ were investigated as excited state quenchers. ${ }^{[37]}$ However, it was rather difficult at that time to incorporate quinone-based relays in an artificial system. The only known example is one in which the half-reactions in two separate aqueous compartments are connected via an organic layer containing the relay. ${ }^{[38]}$ As far as reported, no other HER system, including ours, worked with hydroquinones as SEDs. The successful implementation of a quinone/hydroquinone-based electron shuttle in a HER scheme was probably prevented by the fast recombination of the semiquinone radical or quinone with the reduced PS- . We found that many hydroquinones acted as reversible electron relays in the presence of TCEP and the HER reaction was set on. As a general trend, many hydroquinones are versatile electron relays, depending on their redox properties. The reactions with the $\mathrm{H}_{2} \mathrm{Q}$ 's are generally slower than with ascorbate but persisted over a longer time, leading ultimately to higher TONs than with the ascorbate system. A selection of $\mathrm{H}_{2} \mathrm{Q}$ 's together with the $\mathrm{H}_{2}$ evolution traces is shown in Fig. 6. ${ }^{[39]}$

A detailed mechanistic and kinetic study showed that the rapid quenching of the semiquinone by TCEP or other sacrificial electron donors is the crucial step for making hydroquinones suitable as reductive quenchers. After reductive quenching of the excited state of the photosensitizer, the semiquinone must be trapped very rapidly for increasing the cage escape yields. TCEP does this with a diffusion controlled rate, leading to substantial amounts of produced $\mathrm{H}_{2} \cdot{ }^{[40]}$ Hydroquinones are thus versatile electron relays, following their natural models. As in most steps of artificial photosynthesis which include electron transfer steps, one has to ensure that an electron back transfer does not occur.

\subsection{Conclusions}

In conclusion, artificial photosynthesis in general and the HER reaction in particular consists of many elementary steps. Light ex- citation, reductive quenching, the trapping of the mono-oxidized sacrificial electron donor, the electron transfer to the WRC, its protonation and eventual subsequent reduction in combination with another protonation must run in a highly concerted way. Since the overall reaction is thermodynamically uphill, most intermediates are highly reactive and will decompose or undergo side reactions if left silent in these states over an extended time period. Any sort of way out will affect performance or kill the process entirely. Changing one of the component's composition for improving its properties such as the overpotential will interfere with the catalytic cycles. This interference may be positive or negative but it will be there and eventually entail a need to change the other components as well. Thus, albeit "just" being a two electrons two protons process, to achieve a working system is highly demanding since all involved processes are interlocked into each other and disturbing one means to disturb them all. Finally, beside the kinetic and mechanistic aspects, the catalysts and other parts for HER need to be synthesized, often the 'rate limiting step' in pushing towards a rapid and well performing system.

\section{Acknowledgements}

The authors acknowledge financial support through the University Research Priority Project (URPP) 'LightChEC' and the Swiss National Science Foundation project CRSII2_160801/1

Received: December 14, 2020

[1] a) Z. J. Han, R. Eisenberg, Acc. Chem. Res. 2014, 47, 2537, https://doi.org/10.1021/ar5001605; b) K. Maeda, K. Domen, J. Phys. Chem. Lett. 2010, 1, 2655, https://doi.org/10.1021/jz1007966; c) S. Berardi, S. Drouet, L. Francas, C. Gimbert-Surinach, M. Guttentag, C. Richmond, T. Stoll, A. Llobet, Chem. Soc. Rev. 2014, 43, 7501, https://doi.org/10.1039/C3CS60405E; d) V. Balzani, A. Credi, M. Venturi, 
ChemSusChem 2008, 1, 26, https://doi.org/10.1002/cssc.200700087; e) C. Figueres, C. Le Quere, A. Mahindra, O. Bate, G. Whiteman, G. Peters, D. Guan, Nature 2018, 564, 27, https://doi.org/10.1038/d41586-018-07585-6

[2] a) N. S. Lewis, D. G. Nocera, Proc. Natl. Acad. Sci. USA 2006, 103, 15729 , https://doi.org/10.1073/pnas.0603395103; b) D. G. Nocera, Acc. Chem. Res. 2017, 50, 616, https://doi.org/10.1021/acs.accounts.6b00615; c) A. Borgschulte, Front. Energy Res. 2016, 4 https://doi.org/10.3389/fenrg.2016.00011

[3] F. M. Toma, A. Kudo, R. Van de Krol, L. Z. Wang, ACS Energy Lett. 2017, 2, 2725, https://doi.org/10.1021/acsenergylett.7b01079.

[4] C. McGlade, P. Ekins, Nature 2015, 517, 187, https://doi.org/10.1038/nature14016.

[5] N. Armaroli, V. Balzani, Angew. Chem. Int. Ed. 2007, 46, 52, https://doi.org/10.1002/anie.200602373

[6] a) M. Goetz, J. Lefebvre, F. Moers, A. M. Koch, F. Graf, S Bajohr, R. Reimert, T. Kolb, Renew. Energ. 2016, 85, 1371, https://doi.org/10.1016/j.renene.2015.07.066; b) A. Ramirez, S. M. Sarathy, J. Gascon, Trends Chem. 2020, 2, 785, https://doi.org/10.1016/j.trechm.2020.07.005

[7] a) A. Heller, Acc. Chem. Res. 1981, 14, 154, https://doi.org/10.1021/ar00065a004; b) M. Carmo, D. L. Fritz, J. Merge, D. Stolten, Int. J. Hydro. Energy 2013, 38, 4901, https://doi.org/10.1016/j.ijhydene.2013.01.151; c) M. A. Laguna-Bercero, $J$. Power Sources 2012, 203, 4, https://doi.org/10.1016/j.jpowsour.2011.12.019.

[8] J. Huang, K. L. Mulfort, P. W. Du, L. X. Chen, J. Am. Chem. Soc. 2012, 134, 16472, https://doi.org/10.1021/ja3062584.

[9] D. Marxer, P. Furler, J. Scheffe, H. Geerlings, C. Falter, V. Batteiger, A. Sizmann, A. Steinfeld, Energ. Fuel. 2015, 29, 3241, https://doi.org/10.1021/acs.energyfuels.5b00351.

[10] B. B. Zhang, L. C. Sun, Chem. Soc. Rev. 2019, 48, 2216, https://doi.org/10.1039/C8CS00897C.

[11] G. W. Brudvig, J. N. H. Reek, K. Sakai, L. Spiccia, L. C. Sun, Chempluschem 2016, 81, 1017, https://doi.org/10.1002/cplu.201600436.

[12] a) F. S. Li, K. Fan, B. Xu, E. Gabrielsson, Q. Daniel, L. Li, L. C. Sun, J. Am. Chem. Soc. 2015, 137, 9153, https://doi.org/10.1021/jacs.5b04856; b) D. G. Nocera, Acc. Chem. Res. 2012, 45,767,https://doi.org/10.1021/ar2003013;c)S.Y.Reece,J.A.Hamel,K.Sung, T. D. Jarvi, A. J. Esswein, J. J. H. Pijpers, D. G. Nocera, Science 2011, 334, 645 , https://doi.org/10.1126/science.1209816; d) K. Fan, F. S. Li, L. Wang, Q. Daniel, E. Gabrielsson, L. C. Sun, Phys. Chem. Chem. Phys. 2014, 16, 25234 , https://doi.org/10.1039/C4CP04489D; e) J. S. Luo, J. H. Im, M. T. Mayer, M. Schreier, M. K. Nazeeruddin, N. G. Park, S. D. Tilley, H. J. Fan, M. Gratzel, Science 2014, 345, 1593, https://doi.org/10.1126/science.1258307.

[13] M. E. El-Khoulya, E. El-Mohsnawy, S. Fukuzumi, J. Photochem. Photobiol. C 2017, 31, 36, https://doi.org/10.1016/j.jphotochemrev.2017.02.001

[14] a) B. A. Pinaud, J. D. Benck, L. C. Seitz, A. J. Forman, Z. B. Chen, T. G. Deutsch, B. D. James, K. N. Baum, G. N. Baum, S. Ardo, H. L. Wang, E. Miller, T. F. Jaramillo, Energ. Environ. Sci. 2013, 6, 1983, https://doi.org/10.1039/C3EE40831K; b) J. W. Ager, M. R. Shaner, K. A. Walczak, I. D. Sharp, S. Ardo, Energ. Environ. Sci. 2015, 8, 2811, https://doi.org/10.1039/C5EE00457H.

[15] a) D. Merki, X. L. Hu, Energ. Environ. Sci. 2011, 4, 3878, https://doi.org/10.1039/C1EE01970H; b) H. Vrubel, X. L. Hu, ACS Catal. 2013, 3, 2002, https://doi.org/10.1021/cs400441u.

[16] K. E. Dalle, J. Warnan, J. J. Leung, B. Reuillard, I. S. Karmel, E. Reisner, Chem. Rev. 2019, 119, 2752, https://doi.org/10.1021/acs.chemrev.8b00392.

[17] a) N. Queyriaux, R. T. Jane, J. Massin, V. Artero, M. Chavarot-Kerlidou, Coord. Chem. Rev. 2015, 304, 3, https://doi.org/10.1016/j.ccr.2015.03.014; b) V. Artero, M. Chavarot-Kerlidou, M. Fontecave, Angew. Chem. Int. Ed. 2011, 50, 7238, https://doi.org/10.1002/anie.201007987.

[18] a) M. Razavet, V. Artero, M. Fontecave, Inorg. Chem. 2005, 44, 4786, https://doi.org/10.1021/ic050167z; b) X. L. Hu, B. S. Brunschwig, J. C. Peters, J. Am. Chem. Soc. 2007, 129, 8988, https://doi.org/10.1021/ja067876b.

[19] M. A. Gross, A. Reynal, J. R. Durrant, E. Reisner, J. Am. Chem. Soc. 2014, 136, 356, https://doi.org/10.1021/ja410592d.

[20] a) S. C. Marinescu, J. R. Winkler, H. B. Gray, Proc. Natl. Acad. Sci. USA 2012, 109, 15127, https://doi.org/10.1073/pnas.1213442109; b) J. L. Dempsey, B. S. Brunschwig, J. R. Winkler, H. B. Gray, Acc. Chem. Res. 2009, 42, 1995, https://doi.org/10.1021/ar900253e; c) C. Costentin, J. M. Saveant, J. Am. Chem. Soc. 2017, 139, 8245, https://doi.org/10.1021/jacs.7b02879.

[21] a) A. Call, F. Franco, N. Kandoth, S. Fernandez, M. Gonzalez-Bejar, J. Perez-Prieto, J. M. Luis, J. Lloret-Fillol, Chem. Sci. 2018, 9, 2609,
https://doi.org/10.1039/C7SC04328G; b) N. Queyriaux, E. Giannoudis, C. D. Windle, S. Roy, J. Pecaut, A. G. Coutsolelos, V. Artero, M. Chavarot-Kerlidou, Sustain. Energ. Fuels 2018, 2, 553 , https://doi.org/10.1039/C7SE00428A; c) S. Grau, M Schilling, D. Moonshiram, J. Benet-Buchholz, S. Luber, A Llobet, C. Gimbert-Surinach, ChemSusChem 2020, 13, 2745, https://doi.org/10.1002/cssc.202000283; d) D. Dolui, S. Ghorai, A. Dutta, Coord. Chem. Rev. 2020, 416, 213335 e) W. T. Eckenhoff, Coord. Chem. Rev. 2018, 373, 295, https://doi.org/10.1002/ejic.202000564.

[22] A. Dutta, A. M. Appel, W. J. Shaw, Nat. Rev. Chem. 2018, 2, 244 , https://doi.org/10.1038/s41570-018-0032-8.

[23] a) M. Guttentag, A. Rodenberg, C. Bachmann, A. Senn, P. Hamm, R. Alberto, Dalton Trans. 2013, 42, 334, https://doi.org/10.1039/C2DT31699D; b) C. Bachmann, M. Guttentag, B. Spingler, R. Alberto, Inorg. Chem. 2013, 52, 6055, https://doi.org/10.1021/ic4004017.

[24] a) A. Rodenberg, M. Orazietti, B. Probst, C. Bachmann, R. Alberto, K. K. Baldridge, P. Hamm, Inorg. Chem. 2015, 54, 646 , https://doi.org/10.1021/ic502591a; b) C. Bachmann, PhD thesis University of Zurich, Zurch, 2015.

[25] C. Bachmann, B. Probst, M. Guttentag, R. Alberto, Chem. Commun. 2014, 50, 6737, https://doi.org/10.1039/C4CC01500B.

[26] C. Bachmann, B. Probst, M. Oberholzer, T. Fox, R. Alberto, Chem. Sci. 2016, 7, 436, https://doi.org/10.1039/C5SC02124C.

[27] a) G. M. Brown, B. S. Brunschwig, C. Creutz, J. F. Endicott, N. Sutin, J. Am. Chem. Soc. 1979, 101, 1298, https://doi.org/10.1021/ja00499a051; b) S Aoi, K. Mase, K. Ohkubo, S. Fukuzumi, Chem. Commun. 2015, 51, 15145 , https://doi.org/10.1039/C5CC05064B; c) B. B. Beyene, C.-H. Hung, Sust. Ener. Fuels 2018, 2, 2036, https://doi.org/10.1039/C8SE00253C.

[28] a) C. Costentin, M. Robert, J. M. Saveant, Acc. Chem. Res. 2015 48, 2996, https://doi.org/10.1021/acs.accounts.5b00262; b) A. J Morris, G. J. Meyer, E. Fujita, Acc. Chem. Res. 2009, 42, 1983, https://doi.org/10.1021/ar9001679.

[29] a) S. Ogawa, R. Narushima, Y. Arai, J. Am. Chem. Soc. 1984, 106, 5760, https://doi.org/10.1021/ja00331a074; b) S. Ogawa, T. Uchida, T. Uchiya, T. Hirano, M. Saburi, Y. Uchida, J. Chem. Soc. Perkin Trans. 1990, 1649, https://doi.org/10.1039/P19910001661.

[30] E. Joliat, S. Schnidrig, B. Probst, C. Bachmann, B. Spingler, K. K. Baldridge, F. von Rohr, A. Schilling, R. Alberto, Dalton Trans. 2016, 45, 1737 , https://doi.org/10.1039/C5DT04426J.

[31] S. Schnidrig, PhD thesis University of Zurich, Zurich, 2017.

[32] E. Joliat, PhD thesis University of Zurich, Zurich, 2019.

[33] E. Joliat-Wick, N. Weder, D. Klose, C. Bachmann, B. Spingler, B. Probst, R. Alberto, Inorg. Chem. 2018, 57, 1651, https://doi.org/10.1021/acs.inorgchem.7b02992.

[34] N. Weder, PhD thesis University of Zurich, Zurich, 2020.

[35] a) L. Zeininger, L. Portilla, M. Halik, A. Hirsch, Chem. Eur. J. 2016, 22, 13506, https://doi.org/10.1002/chem.201601920; b) B. J. Brennan, M. J. Llansola Portoles, P. A. Liddell, T. A. Moore, A. L. Moore, D. Gust, Phys. Chem. Chem. Phys. 2013, 15, 16605, https://doi.org/10.1039/C3CP52156G; c) E. Bae, W. Choi, P. J., H. S. Shin, S. B. Kim, J. S. Lee, J. Phys. Chem. C 2004, 108, 14093, https://doi.org/10.1021/jp047777p.

[36] N. Weder, B. Probst, L. Severy, R. J. Fernandez-Teran, J. Beckord, O. Blacque, S. D. Tilley, P. Hamm, J. Osterwalder, R. Alberto, Catal. Sci. Technol. 2020, 10, 2549, https://doi.org/10.1039/D0CY00330A.

[37] K. Kalyanasundaram, Coord. Chem. Rev. 1982, 46, 159, https://doi.org/10.1016/0010-8545(82)85003-0.

[38] T. Ohno, K. Fujihara, K. Sarukawa, E. Tanigawa, M. Matsumura, Z. Phys. Chem. 1999, 213, 165.

[39] M. Mosberger, PhD thesis University of Zurich, Switzerland, Zurich, 2019.

[40] A. Rodenberg, M. Orazietti, M. Mosberger, C. Bachmann, B. Probst, R. Alberto, P. Hamm, ChemPhysChem 2016, 17, 1321, https://doi.org/10.1002/cphc.201501085.

\section{License and Terms}

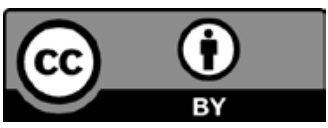

This is an Open Access article under the terms of the Creative Commons Attribution License CC BY 4.0. The material may not be used for commercial purposes.

The license is subject to the CHIMIA terms and conditions: (http:// chimia.ch/component/sppagebuilder/?view = page\&id=12).

The definitive version of this article is the electronic one that can be found at https://doi.org/10.2533/chimia.2021.180 